\title{
Awareness and Practice of Biosecurity Measures in Small Scale Poultry Production in Ekiti State, Nigeria
}

\author{
Ajewole, Oladele Charles andAkinwumi,AyodeleAdekunle \\ Department of Agricultural Economics and Extension Services \\ Ekiti State University, PMB 5363, Ado-Ekiti, Nigeria.
}

\begin{abstract}
The high susceptibility of poultry to disease outbreaks makes a comprehensive biosecurity technology a necessary practice in poultry farms to protect the farms from both intentional and unintentional threats from biological agents. Therefore this study evaluated the awareness and practice of biosecurity measures in small scale poultry production in Ekiti State, Nigeria. A total of 80 respondents were randomly selected for the study. Data were obtained with the aid of a pre tested structured questionnaire. The result shows that the most practiced biosecurity measures in the study area are the ones relating to regular clearing of the poultry environment, regular washing of the feeding and drinking troughs while the least observed one is the quarantine of the new birds. Also the result of the regression analysis shows that the level of education, farm size, formal training in poultry production and number of extension visits all have significant positive influence on the sampled farms' biosecurity control score while age, number of household labour, and distance from the nearest poultry farm shows significant negative influence on the farms' biosecurity control score. Equally, the result of the likert rating scale shows that the poultry farmers have a good knowledge of biosecurity measures with overall biosecurity knowledge index of 3.22. The study therefore recommends among other things the intensive sensitization of the poultry farmers through workshop and field days seminars by appropriate agents on the benefit of adhering strictly to biosecurity measures on their farms.
\end{abstract}

Key words:Awareness, Biological agents, Biosecurity measures, Disease outbreaks, Poultry, Practice.

\section{Introduction}

The recurrent global disease outbreak in poultry farms has made the practice of biosecurity an important practice to protect the poultry farms from intentional and unintentional threat of any disease producing agents on the farms. [1] defined biosecurity in poultry farming as a set of measures designed to prevent disease causing organisms from coming in contact with resident birds on the farm. These measures are a combination of systems and practices to reduce the burden of any disease producing agent on the farms and therefore prevent the adverse effects of diseases on the farm. According to [2] poultry farm-level of biosecurity varies from simple measures such as cleaning the shed to more technologically advanced measures such as using high pressure water sprayers to clean cars passing through the farm gate. Poultry may get diseases from a variety of source, including people, equipment, supplies, vehicles, pets and wild animals, dust, contaminated feed and water supplies, farm wastes, feathers, dropping and manure [3]. They stated further that diseases does not only increase mortality, but also could cause slower growth, lower egg production rates, reduce product quality and lower customer satisfaction, which all lead to enormous financial losses to producers and could be reflected in price increases to the consumers.

For any biosecurity programme to achieve desired impact a comprehensive biosecurity programs which will be religiously followed must be developed. In general a comprehensive biosecurity program should include three major elements: isolation, traffic control, and sanitation [4], [5]. Isolation can be considered in terms of time, that is: "time between in-out and refilling a poultry house", distance between farms or houses in a farm, and physical barriers such as fences, showers, foot baths all of which limit the spread of disease agents [5]. Traffic control includes restricting human, equipment, and animal movement onto the farm, and movement patterns within the farm. According to [3]the most common visitors to the poultry farms are the most dangerous because they are likely to have had recent contact with other poultry farms. Included in this group are feed delivery trucks and their drivers, field service personnel, vector-control personnel, hatchery and transport trucks and tier, veterinarians and utility personnel, and repairmen and guests. Sanitation on the other hand refers to the cleaning and disinfection of poultry housing, people, materials, and equipment [4]. The goal of farm sanitation is to maintain a healthy environment for the chicken flock. Sanitation is an important component of biosecurity because it reduces the likelihood of poultry pathogens coming in contact with the birds.In addition to reducing the potential of introducing and spread of disease causing organisms onto and between farms, a diligently followed biosecurity practice will keep biological agents such as viruses, bacteria, fungi, and protozoa which are responsible for disease outbreak at bay on the farm. Generally, biosecurity measures can be categorized as either external or internal measures. External biosecurity measures are those measures taken to prevent the entry of 
new diseases into a flocks or production groups, while internal biosecurity measures are those measures taken to prevent the spread of a disease already in the flocks.

Although [3] opined that the poultry industry, in many parts of the world has been applying some kind of biosecurity measures for many years. [1] identified three key levels of biosecurity as follows, (i) Conceptual biosecurity that involves site planning and location of the farms, (ii) Structural biosecurity which involves the design of the farm and buildings, and (iii) Operational biosecurity that involves day-to-day running of the farm. However, to determine the level of biosecurity that is practicable for a particular farm, [6] stated that the following three factors should be considered: economics, common sense and relative risk factors. Also according to[5] to determine the cost-benefit of a biosecurity program, one should consider facts about the economics associated with the type of productionand the costs of implementing a comprehensive biosecurity program along with estimates of the relative risk and cost of diseases. This notwithstanding, the growing trend in ensuring health certification as an indicator of quality assurance in purchasing and consumption of poultry products among consumers will continue to make biosecurity practices very crucial to the maintenance of highest possible poultry health status which is vital to the sustainability and profitability of poultry farms. However, based on field observations, the extent of biosecurity technology implementation in Ekiti state is still very much lower in comparison to recommended biosecurity practice implementation. Therefore, in order to provide a recommendation for improving farm biosecurity, it is essential to study the knowledge and the use of biosecurity measures among poultry farmers in Ekiti State. This will assist policy maker in formulating policies that will assist and encourage poultry farmers to embrace the use of biosecurity measures and keep incidence of disease outbreak on their farms at bay if not completely eradicated.

\subsection{Study Area}

\section{Methodology}

This study was conducted in Ekiti State, Nigeria. The state which lies entirely within the tropics is located between Longitude $4^{0} 45^{\prime}$ to $5^{0} 45^{\prime}$ East of the Greenwich meridian and latitude $7^{0} 15^{\prime}$ to $8^{0} 5^{\prime}$ North of the equator. It lies south of Kwara and Kogi states while it is bounded by Osun state on the west. It is equally bounded in the south and in the east by Ondo state.

The state enjoys a typical tropical climate with two distinct seasons, the rainy season which last roughly from April to October and the dry season which prevails for the remaining months (November to March). Temperature ranges between $21^{\circ} \mathrm{C}$ and $28^{\circ} \mathrm{C}$ with high humidity. Tropical forest exists in the southern part of the state while the guinea savannah occupies the Northern peripheries. The farmers in this state were engaged in many agricultural activities to sustain their living such as livestock production, cultivation of cash crops, food crops and tree crops.

\subsection{Sampling technique}

The study population consists of poultry farmers in Ekiti State. A total number of five Local Government Areas viz:Ado,Ikere , Irepodun/Ifelodun,Ido/ Osi,and Ikole local government areas were purposively selected for the study due to the dominance of poultry farmers in these areas. A total of 16 poultry farmers were randomly selected from each of the localgovernment areas based on the list of poultry farmers obtained as fadama users group from the state fadama programme coordination office. In all a total of 80 respondents were selected for interview.Data were collected with the aid of a pre tested structured questionnaire. Information were collected on socio-economic characteristics of the respondents such as age, sex, income level, farming experience e.t.c, production characteristics such as farm size, type of birds reared, type of poultry system used and on the individual farmers' awareness and practices of biosecurity measures. These were augmented with observations from the farmers' farms by the researcher.

\subsection{Analytical technique}

Data collected were analyzed using thefollowing analytical techniques to achieve the objectives of the study

(i) Descriptive Analysis

This entails the use of frequency counts, means, percentages and tabulation to describe,summarize, and categorize the socioeconomic characteristics of the respondents, awareness and practice of various biosecurity measures.

\section{(ii) Regression Analysis}

Linear regression model was used to evaluate the relationship between the respondents' farm biosecurity control score and the socioeconomic characteristics. The linear regression model is implicitly specified as follows;

$\mathrm{Y}=\mathrm{f}\left(\mathrm{X}_{1}, \mathrm{X}_{2}, \mathrm{X}_{3}, \mathrm{X}_{4}, \mathrm{X}_{5}, \mathrm{X}_{6}, \mathrm{X}_{7}, \mathrm{X}_{8}\right)$

Where: $Y=$ Biosecurity Control Score measured as the total number of biosecurity measures practiced by the individual farmers on their farms 
Awareness and Practice of Biosecurity Measures in Small Scale Poultry Production in Ekiti ....

$\mathrm{X}_{\mathrm{i}}=$ Independent Variables (where $\mathrm{I}=1,2,3$,

Table 1: Measurement and Description of the Independent/Explanatory variables

\begin{tabular}{ll|l}
\hline \multicolumn{2}{c|}{ Explanatory variable } & Description \\
\hline $\mathrm{X}_{1}=$ & Age & Continuous (years) \\
$\mathrm{X}_{2}=$ & Gender & Dichotomous, Male 1; Female 0 \\
$\mathrm{X}_{3}=\quad$ Farming Experience & Continuous (years of active poultry farming) \\
$\mathrm{X}_{4}=\quad$ Level of Education & Continuous (years) \\
$\mathrm{X}_{5}=\quad \begin{array}{l}\text { Household labour Size } \\
\text { farm) }\end{array}$ & Continuous (numbers of house members thatworks in the \\
$\mathrm{X}_{6}=\quad$ Formal training in poultry farming & Dichotomous(Yes $=1:$ No $=0)$ \\
$\mathrm{X}_{7}=\quad$ Size of Farm & Continuous (number of birds on the farm) \\
$\mathrm{X}_{8}=\quad$ Extension Contact & Continuous (number of extension visits received in the \\
lastsix months) & \\
$\mathrm{X}_{9}=$ Distance from nearest Farm & Continuous (Km) \\
\hline
\end{tabular}

\section{(iii) Likert Rating Scale}

This scale was used to analyze the respondents' knowledge of biosecurity measures. Various opinion statements were generated and the farmers were ask to rate these statement based on their knowledge of biosecurity measures as follows on a scale of 1-5; Strongly disagree was awarded 1 point, disagree was awarded 2 point, undecided was awarded 3 point, agree was awarded 4 point. And strongly agree was awarded 5 point.Average index value was then generated to give remark on each of the listed statements. A mean score of 3 and above was classified as agreed while a mean score less than 3 was classified as disagreed.

\subsection{Socioeconomic Characteristics of the Respondents}

\section{Results and Discussion}

Table 2 gives a summary of the socioeconomic characteristics of the respondents. As shown in Table the average age of the respondents is 46.85 years, this show that the sampled farmers were relatively young and within the active work age range with a standard deviation of 10.63 . Majority of the respondents $60.9 \%$ were male and about $33.75 \%$ of the respondents have primary education while only $3.75 \%$ has never been to any formal school. About $81.25 \%$ of the respondents did not receive any extension visit for the past six months from the date of data collection. Also, only $11.25 \%$ of the respondents keep above 1000 birds in their farms this shows that majority of the farmers can be classified as small scale poultry farmer. Majority of the respondents $70.9 \%$ engaged less than four household members as labour and $66.25 \%$ of the respondents have gone through trainings in poultry farming. The average distance between the poultry farms is about $5.68 \mathrm{~km}$, however, majority of the farms $77.50 \%$ have a distance of above Eight kilometers between them.

Table 2: Socioeconomic Characteristics of the Respondents

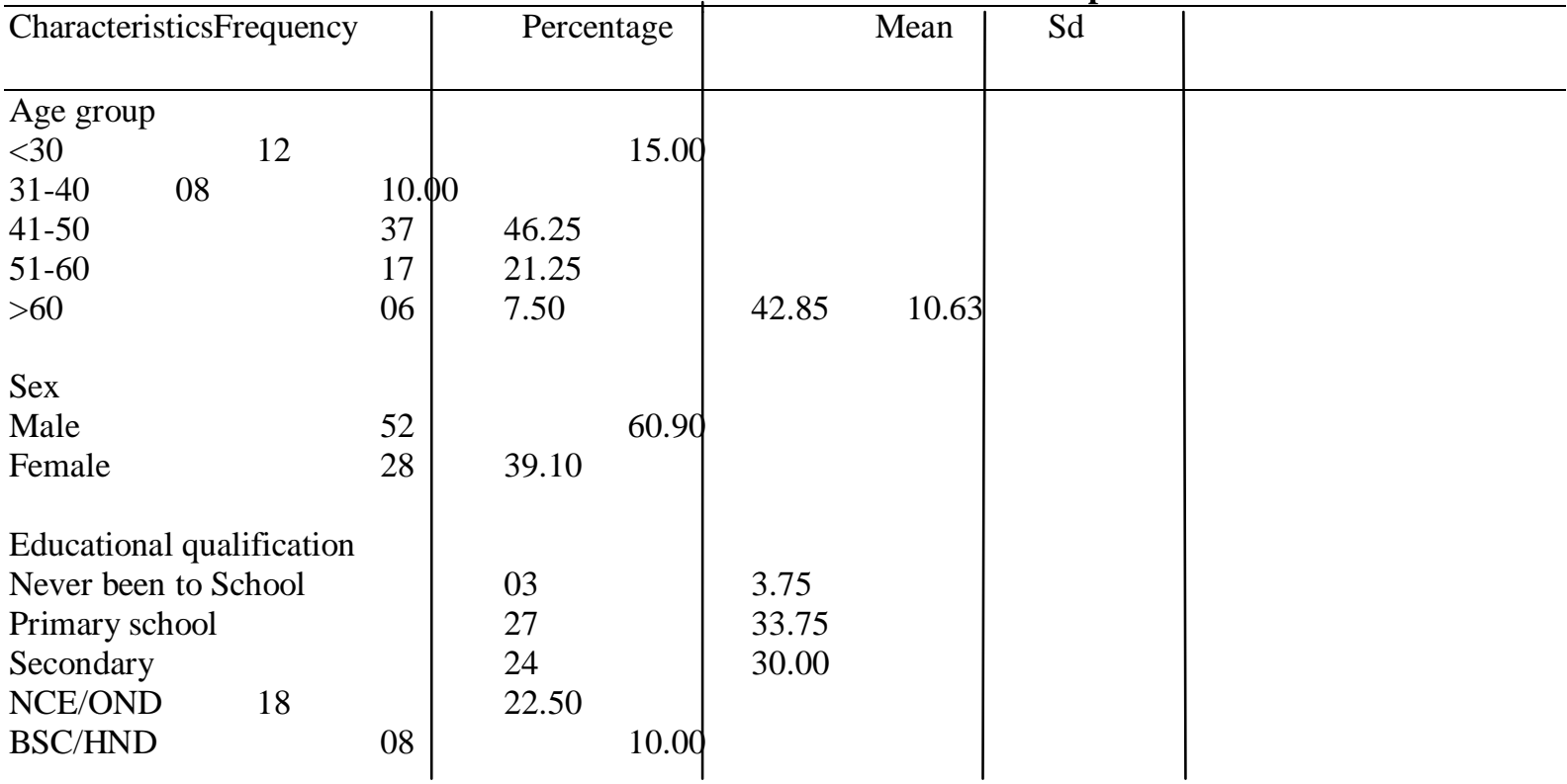


Table 2 Continued

Extension officer visits

Yes

No

Farm size

$<200$ birds

201-400 birds

401-600 birds

601-800 birds

801-1000 birds

$>1000$ birds

Household labour size

$<4$

4-8

$>8$

03

Formal training in poultry production

Yes

No

53

Distance from the nearest poultry farm

$<4$

$4-8$

$>8$

15

62

Poultry production experience

$<5$

6-10

$11-15$

08

$>15$

23
31

Source: Field Survey, 2013.

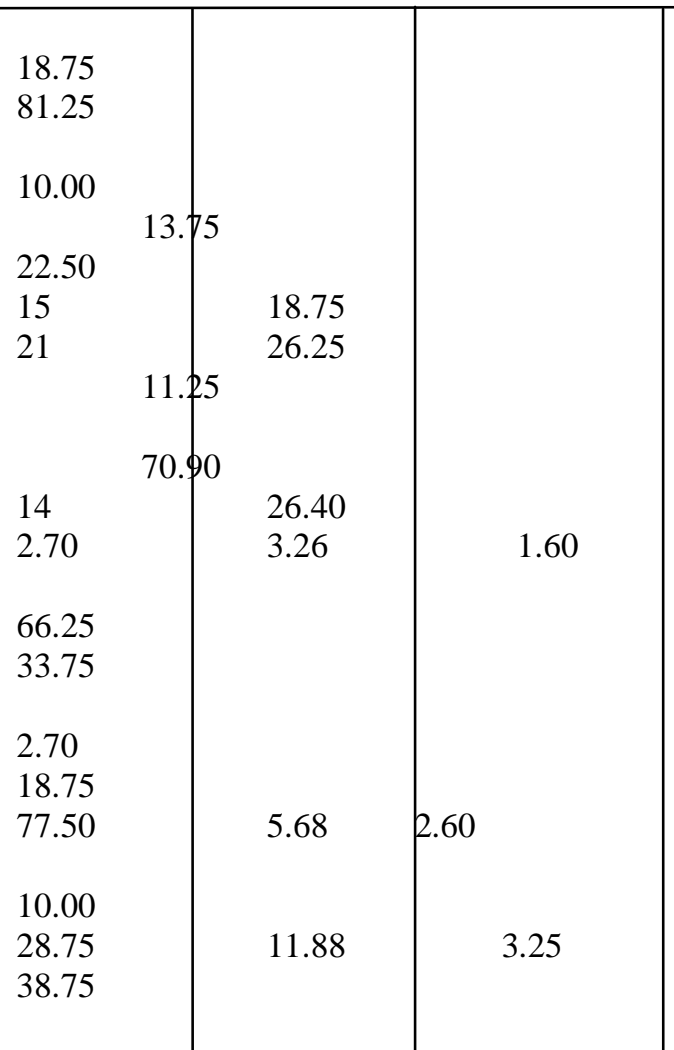

\subsection{Awareness and Practice of Biosecurity Measures}

The level of awareness and practice of basic biosecurity measures by the respondents is presented in Table3. Interestingly all the respondents claimed to be aware of all the listed basic biosecurity measures. However, it is the measures relating to general sanitations of the pens like regular clearing of the surroundings, regular packing of litters, regular cleaning of feeding and drinking troughs that recorded 100\% compliance among the farmers. Also isolation of infected birds and physical security of the farms recorded $100 \%$ positive response while other measures recorded various level of response as presented in Table 3

Table 3: Awareness and Practices of Biosecurity Measures.

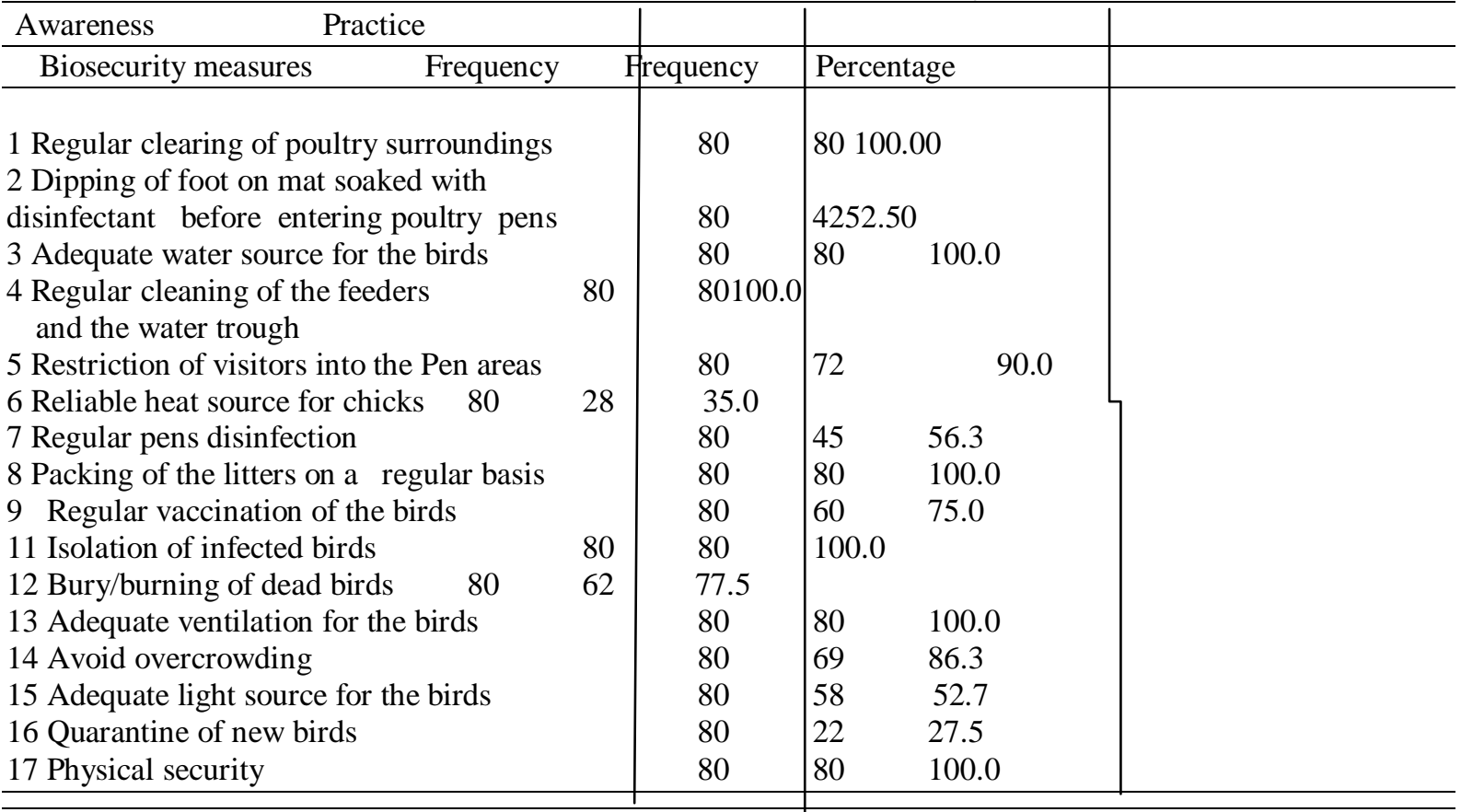


Source: Field Survey, 2013.

\subsection{Factors Influencing the Use of Biosecurity Measures.}

The results of multivariate regression analysis used to examine the relationship between individual farmers Biosecurity Control Score(BCS) and some socioeconomic characteristics of the respondents is presented in Table 4. From the Table positive significant relationship was established for level of education, formal training in poultry production, farm size and number of extension visits received which means that any increase in the level of these variables will increase the respondents BCS. On the other hand age, household labour size, and distance from the nearest farm shows significant negative relationship with BCS meaning that any increase in these variables will reduce the respondents BCS.

Table 4: Regression Results of Factor Influencing Use of Biosecurity Measures.

\begin{tabular}{l|l|l}
\hline Variables & Coefficient & $\mathrm{p}>/ \mathrm{t} /$ \\
\hline Constant & 0.420 & 0.000 \\
Age & $-0.002^{*}$ & 0.079 \\
Sex & 0.008 & 0.697 \\
Educational qualification & $0.025^{* *}$ & 0.016 \\
Household labour size & $-0.011^{*}$ & 0.064 \\
Poultry production experience & 0.004 & 0.935 \\
Formal training in poultry production & $0.033^{* * *}$ & 0.006 \\
Farm size & $0.078^{* *}$ & 0.053 \\
Extension Contact & $0.032^{*}$ & 0.063 \\
Distance from nearest farm & $-0.014^{*}$ & 0.073 \\
\hline
\end{tabular}

Source: Data Analysis, 2013.

* Significant at $10 \%$

** Significant at $5 \%$

$* * *$ Significant at $1 \%$

\subsection{Respondents' Knowledge of Biosecurity Measures.}

The result of likert rating scale used to analyze the respondents' knowledge of biosecurity measures is as presented in Table 5. To arrive at the respondents' biosecurity knowledge rating, a rating index termed Biosecurity Knowledge Index Value (BKIV) calculated as the mean value score was generated for each of the statements. The overall BKIV of 3.17shows that the sampled farmers have a good knowledge of biosecurity measures.Specifically, the respondents agreed with six out of the ten generated biosecurity knowledge perception statements while they disagreed with four statements.

Table 5: The Respondents' Knowledge of Biosecurity Measures.

\begin{tabular}{|c|c|c|c|c|c|c|c|}
\hline UN & DA & SD & BKIV & Remarl & & & \\
\hline Biosecurity measures adoption & & & & & & & \\
\hline $\begin{array}{l}\text { will enhance productivity } \\
\text { Biosecurity practices improve }\end{array}$ & 29 & 32 & 07 & 09 & 03 & 3.94 & Agree \\
\hline growth performance & 03 & 17 & 34 & 22 & 04 & 2.91 & Disagree \\
\hline $\begin{array}{l}\text { Biosecurity practice reduce } \\
\text { disease outhreak on the farm }\end{array}$ & & & & & & & \\
\hline $\begin{array}{l}\text { disease outbreak on the farm } \\
\text { Biosecurity measures adoption }\end{array}$ & 27 & 42 & 08 & 03 & 00 & 4.16 & Agree \\
\hline will reduce disease transmission & 35 & 36 & 05 & 03 & 01 & 4.29 & Agree \\
\hline $\begin{array}{l}\text { Biosecurity measures are } \\
\text { expensive to practice }\end{array}$ & 07 & 16 & 34 & 15 & 08 & 2.99 & Disagree \\
\hline $\begin{array}{l}\text { Biosecurity measures are } \\
\text { difficult to practice }\end{array}$ & 03 & 13 & 05 & 45 & 14 & 2.33 & Disagree \\
\hline Biosecurity practice require & & & & & & & \\
\hline Technicalknow-how & 06 & 10 & 07 & 24 & 33 & 2.15 & Disagree \\
\hline $\begin{array}{l}\text { Biosecurity practice enhance } \\
\text { poultry products quality }\end{array}$ & 09 & 42 & 12 & 08 & 09 & 3.43 & Agree \\
\hline $\begin{array}{l}\text { Biosecurity measures adoption } \\
\text { increase total farm income }\end{array}$ & 19 & 37 & 03 & 15 & 06 & 3.60 & Agree \\
\hline farm size expansion & 02 & 09 & 21 & 34 & 14 & 2.35 & Disagree \\
\hline
\end{tabular}

Source: Data Analysis, 2012. 


\section{Conclusion}

The study shows that the poultry farmers have a good knowledge of the basic biosecurity measures needed for day to day running of poultry farms especially the ones dealing with sanitation of the farms. Although a good number of the farmers did not adhere strictly to the measures. Therefore, based on the findings on the farms visited, thestudy recommends among other things the intensive sensitization of the poultry farmers through workshop and field days seminars by appropriate agents on the benefit of adhering strictly to biosecurity measures on their farms. Also, specific biosecurity program should be developed for individual poultry farm according to their particular need and situations with the cooperation of the decision makers and farm veterinarian to ensure the success of the program

\section{References}

[1]. J. Woodger,Poultry Biosecurity: .Farm Care International Ltd 24e Norwich StreetDereham, Norfolk England NR19 1BX2005

[2]. Sri HerySusilowati Muhammad Iqbal, and Ian Patrick :The relationship between biosecurity and farmer and farm characteristics. Biosecurity Workshop, June 7-8, 2010, Bogor, West Java

[3]. Al-Saffar A, Al-Nasser, A. Al-Haddad A Al-Bahouh M and Mashaly M,Principles of Poultry Biosecurity Program Kuwait, ( Kuwait Institute for Scientific Research,2006)

[4]. Cardona C. J, and Douglas Kuney,( 2001): Biosecurity on Chicken Farms. Commercial Chicken Meat and Egg production. Fifth edition.Edited by Donald D. Bell and William D. Weaver.(Kluwer Academic Publishers, P.O. Box 322,3300 AH Donrdrecht,2001)The Nethelands. Pg:543- 556.

[5]. J. P. Vaillancourt, How do you determine the cost-benefit of a biosecurity system? Zootecnica-International 24 2001, $20-27$.

[6]. J. S., Jeffrey, Biosecurity rules for poultry flocks. Misset-World Poultry 13, 1997:101. 